\title{
Staff perceptions of best practice for information transfer about multi-trauma patients on discharge from the Emergency Department: a focus group study.
}

Keywords: Nursing Handover, Communication, Transfer, Emergency Department, Focus Groups, Trauma, Patient Information, Patient Safety, Qualitative Study.

\begin{abstract}
Aims \& Objectives: To understand: (a) staff perceptions of best practice for information transfer for multi-trauma patients on discharge from the emergency department; (b) what information should be conveyed at transfer and (c) how information is transferred.
\end{abstract}

Background: Information transfer for multi-trauma patients is an integral factor for continuity of care, safety, quality assurance and patient outcomes, however has not been the focus of previous studies.

Design: This was a qualitative study using focus group interviews.

Methods: Data were collected during focus group interviews across five clinical areas. Themes were derived from the data with consensus from three data coders. Purposive sampling was used and included staff caring for trauma patients during patient transition out of the Emergency Department. Participants were representatives of the Emergency Department, Perioperative Care, Intensive Care Unit, High Dependency Care Unit and the Trauma Service Unit. Twenty-six Registered Nurses and two Medical Officers participated.

Results: Five focus group interviews were held. Themes emerged from the data including; 'Variability', 'Continuity' and 'Putting the pieces together'. The first three themes were all influenced by the fourth theme of 'Values/Context'. Considered together these themes influenced staff perception of the quality of information transfer for multi-trauma patients on discharge from the emergency department. 
Conclusions: Staff perceived best practice for information transfer to be clear, concise, relevant, documentation that travelled with the patient and interactive communication at handover that adhered to agreed principles and a minimum data set specific to trauma patients.

Relevance to clinical practice: Clinicians involved in handover need to actively listen, avoiding 'doing' at the same time, be aware of essential questions to ask about the patient. An agreed expectation between different clinical areas needs to exist about information transfer to reduce variability. The minimum data required to provide ongoing safe care for multitrauma patients is identified.

What does this paper contribute to the wider global clinical community?

- Best practice for information transfer equals clear, concise, relevant information that builds a picture of the patient for receiving staff to reduce possible errors and improve patient outcomes

- Handover should be structured and roles should be clear with expectations agreed upon between different clinical environments.

- Documentation should be comprehensive and should travel with the patient. 


\section{INTRODUCTION:}

Information transfer refers to information exchanged by staff before, at, or after patient transition or handover (Calleja et al. 2011). In trauma care it is integral to the continuing care patients receive across care transitions. Information transfer is a particularly important issue for multi-trauma patients as the complexity of their injuries affect multiple body systems. Their care typically requires multiple staff from multiple specialities such as general surgery, orthopaedics, cardiac surgery and neurosurgery.

\section{BACKGROUND:}

Clinicians and researchers have examined how teams work to enhance patient survival and reduce potential disability (Bergs et al. 2005, Cole \& Crichton 2006, Mackenzie et al. 2004, Xiao \& Moss 2001). In these studies communication has been a common issue, however there have been no comprehensive investigations of information transfer for multi-trauma patients. Instead the focus has been on issues or errors resulting from poor communication, with communication improvement a recurring recommendation (Bergs et al. 2005, Cole \& Crichton 2006, Mackenzie et al. 2004, Xiao et al. 2007).

Communication quality is identified as a significant issue in health care, both nationally and internationally (World Health Organization 2007) and especially in trauma care (Sugrue et al. 1995). A gap exists in the literature about the perceived effects of missing, fragmented, unclear and inconsistent patient care information on the patient. For example McFetridge et al., (2007) found that handover practices for patients transferred from the Emergency department (ED) to the Intensive Care Unit (ICU) were largely unstructured. Their study acknowledged the importance of the health professionals' perspectives in understanding information transfer for multi-trauma patients. 
A recent, similar study focussing on lost clinical information during the transfer of trauma patients from the ED to ICU found that injuries were missed in $24 \%$ of patients and that information discrepancies occurred in $48 \%$ of handovers (Zakrison et al. 2015). Causes of these discrepancies varied from patients having unknown medical histories, variability in handover structure, processes and quality, role discrepancy in relation to handover among disciplines, a lack of understanding of context between ED and ICU and flow disruptions in communication (Zakrison et al. 2015). Solutions focused on improving the whole process of handover between ED and ICU and a consideration of the impact of organisational system aspects, including culture (Zakrison et al. 2015). As such it is essential to understand the process of information transfer for multi-trauma patients from the perspective of the clinicians involved which was an aim of the current study.

\section{Aims}

The aims of the current study were to understand what clinicians perceive to be best practice for information transfer for multi-trauma patients on discharge from the ED; the information that should be conveyed for multi-trauma patients leaving the ED and how multi-trauma patient information is communicated at transition from the ED.

\section{METHODS:}

This was a qualitative inductive study. Focus group interviews were used to collect data. This method was chosen as it enabled access to a number of participants at once and all ideas and data gathered could be explored, confirmed, reinforced or contradicted within the group at the same time (Denscombe 2007, Happell 2007, Webb \& Kevern 2001). Participants also provided historical information about the context of emergency care presentations.

\section{Setting}


The setting for this study was an ED within one trauma service in a major metropolitan city in Queensland, Australia.

\section{Ethics}

Ethical approval was granted by Metro South Human Research Ethics Committee (HREC/09/QPAH/081), and Griffith University Human Research Ethics Committee (NRS/20/09/HREC).

\section{Sample}

Participants for the focus group interviews were clinicians working in roles where patient information was communicated at transition points of care for multi-trauma patients leaving the ED. Clinicians were identified by senior management of each area and an email inviting them to attend a focus group interview was forwarded by a department representative. Group size ranged from three to ten participants. This group size was chosen to ensure that group members had an opportunity for meaningful input (Denscombe 2007, Happell 2007).

\section{Data collection and validation}

Trigger questions for the focus group interviews were formulated based on issues raised in relevant literature and refined by the research team. Questions were modified to the two contexts of giving the handover and transferring the patient (for the ED group) and receiving the handover and patient (all other areas) (see Text Box 1). Each group had the same researcher and a stenographer who transposed the conversation in real time into a Word document. Focus group interviews served multiple purposes in this study in that they were designed to: (1) identify what staff believed was best practice for information transfer, (2) explore how information was transferred along with barriers and conduits to information 
transfer and, by identifying themes in these data; (3) explore what information should be transferred for multi-trauma patients on discharge from the ED.

Text Box 1: Trigger questions for focus groups

\section{Questions used to guide focus groups}

\section{Transfer of patients from ED (for ED staff only)}

1. Consider two recent multi- trauma patient transfers from the ED. One transfer should be for an ideal transfer and the other should be an example of where the transfer of information was not ideal. Can you now tell me about what went wrong, what made you feel the transfer of information was not ideal?

2. In the scenario that was ideal what factors/processes made it ideal?

3. Are there specific pieces of information that you feel are important for any multi-trauma patient? I will list these.

4. Do you feel documented care is important to inform future care? Can you tell me why/why not?

\section{Transfer of patients being received from ED}

1. Consider two recent multi- trauma patient transfers from the ED. One transfer should be for an ideal transfer and the other should be an example of where the transfer of information was not ideal. Can you now tell me about what went wrong, how this impacted on your care for the patient for each scenario?

2. In the scenario that was ideal what factors/processes made it ideal? 
3. Are there specific pieces of information that you need every time for any multi-trauma patient? I will list these.

4. Do you refer to documented past care to help inform your own care? Is documented past care important or useful? Can you tell me why/why not?

Group dynamics were noted by the researcher and field-notes were written immediately after each group. The researcher wrote short notes during the group's discussion of the main ideas and verbally recapped the main points for the group to discuss or agree to after each trigger question had been thoroughly discussed. This directed the discussion to allow everyone who wished to speak to do so. Group members became very involved in seeking consensus and validation of the main points in discussion for particular topics. Transcripts were sent out to the group participants to validate the content of the conversations; however, perhaps due to the vigorous discussion within the focus group, no group members indicated any difference or amendment be made to the transcript.

\section{Data analysis}

Data analysis mirrored the 'Qualitative Data Analysis Process' described by Norwood (Norwood 2010). This was an interactive process where stages of data analysis often overlapped. Stages included in-field reflection, data preparation, data familiarisation, searching for themes and patterns and interpreting and attaching meaning (Norwood 2010). Data saturation was considered when participants felt they had exhausted the topics led by the researcher in each interview and when no new data from the interviews were apparent. Data were first coded for the analysis group by group, and the researcher then compared and contrasted data between groups to identify themes and subthemes.

\section{RESULTS:}


A total of five focus group interviews were conducted across five clinical areas, and a single interview (using the same questions as the focus group) with one clinician who could not attend the focus group due to clinical requirements but wished to have input (see Table 1 for group membership). Participants recruited included registered nurses (RNs) in the ED, Perioperative Services (PERIOP) including anaesthetics, operating theatre and post-operative care unit, High Dependency Unit (HDU), Trauma Services Unit (TSU) and ICU and medical officers (MOs) from the ED and TSU. MOs in surgical, intensive care, neurosurgical and orthopaedic services were invited to take part in the study, but no participants were recruited from this group.

Table 1: Focus group membership

\begin{tabular}{lcc}
\hline $\begin{array}{c}\text { Clinical Department } \\
\text { of participants }\end{array}$ & $\begin{array}{c}\text { Groups } \\
\text { held }\end{array}$ & $\begin{array}{c}\text { Participant numbers and } \\
\text { designation }\end{array}$ \\
\hline Emergency department & 1 & $9 \mathrm{RNs}+1 \mathrm{MO}$ \\
High Dependency Unit & 1 & $3 \mathrm{RNs}$ \\
\hline Perioperative Unit & 1 & $5 \mathrm{RNs}$ \\
Intensive Care Unit & 1 & $6 \mathrm{RNs}$ \\
\hline Trauma Service Unit & 1 group & $3 \mathrm{RNs}$ \\
& 1 interview & $1 \mathrm{MO}$ \\
\hline
\end{tabular}

Four themes emerged from the data. The first three were variability, continuity and putting the pieces together. These three themes were all influenced by the fourth theme of values/context, which formed the basis for identification of issues and good practices and was perceived to moderate how each theme influenced the quality of information transfer (Figure 
1). Further details of subthemes and quotes can be seen in the supplementary table (available online).

$<<$ Insert Figure 1 here $>>$

\section{Variability}

In regard to different expectations among staff between clinical areas and between disciplines variability was the first theme that emerged. Variation was related to skills, knowledge and the application of handing over information, documenting information and even deciding what needed to be documented or handed over. Within the theme of variability there were five subthemes including: expectations; skills or knowledge; information staff chose to hand over or document; quality of the information handover; and process used.

I don't think the expectations are the same. They are two completely different environments. What the ED nurse hands over, she thinks it is useful from her environment. There is that lack of understanding from both departments. You don't know what that other person wants to get out of the handover process. TSU4

It is the importance of the information. Some things I find it important; P8 might not. She might not find it appropriate to hand over but for me it is a big piece of the puzzle. ED9

\section{Continuity}

The next theme uncovered was continuity, which was a term participants used to refer to the sub-themes of people and relational discontinuity; evidence or impact of broken links in information transfer; the impact of resources; how information was transferred, and discrepancy or discontinuity of information. 
You try to, for consistency, but if you have that swap of shift, the more swaps, the more links are broken in the communication. You try to keep the same person with the person who spent the time. But... ED3

Continuity, or issues of discontinuity, was specifically seen in instances where links were maintained or broken in communication cycles, between disciplines, at transfer of the patient between clinical areas and was argued by participants to directly affect patient care.

The next day on the ward round, the handover sheet will say it was the 4th rib and somebody else will say it was the 8th rib... That often happens on the ward round. We have a laugh and get out the X-ray to show which rib it was. TSU4

Where continuity links were maintained, staff felt better patient outcomes were achieved. Where discontinuity occurred or links were broken, then this adversely affected the staff's ability to care appropriately for the patient, thus impacting negatively on the patient's outcomes.

It may be the nurse in HDU or ICU who is not asking the right questions, isn't receiving. The ED nurse is trying to tell her information and she is kind of turned off. It is a two way street. It is not purely ED not giving good information. Sometimes the nurses are not receiving it or not listening or are not aware of which questions to ask. TSU1

\section{Putting the pieces together}

A range of subthemes including putting together a picture, patient transition, planning safe patient care and missing pieces were brought together in the theme of putting the pieces 
together. In this theme, issues surrounded clinicians being able to weave together multiple pieces of information about a patient and their care to make decisions about future care were evident from the data.

Sometimes you are drawing information from one area in one particular case and you draw it from another area. It might be the registrar's note from ED. That is where you are getting information. It might be ED, other paperwork that they have got. You are never getting the same information from the same spot; it's from varying areas. PERIOP2

Something simple like what is under that dressing. We don't know. HDU3

\section{Values/context}

Values about good communication and documentation were commonly espoused by staff across the different clinical areas. The context of being in different clinical areas did not affect the value of documentation and communication, but it did influence the application of those values. For example, while documentation was seen to be important everywhere, in PERIOP, ED and TSU staff accepted that sometimes documentation would fall away if the life or a limb of the patient was threatened, whereas in the ICU and HDU this was not accepted.

What was being done was not being recorded. It was acknowledged that documentation, because of the unwellness of the patient and the urgency to get procedures done, documentation got left...It is not because we sat around and did nothing. It was because we had other activities that were life or limb threatening procedures to be achieved and then documentation at the end. TSU2 
You can't really do anything on hearsay. It has to be documented.

Regardless of what you hear, it can be Chinese whispers, what the actual documentation is - it is probably as important, if not more important, than what your communication handover is. ED3

Variability in practice and of behaviours/performance emerged from data that identified where participants enacted values (e.g. that comprehensive documentation was important etc.). Values were what participants from different clinical and discipline areas described as the ideal practices in information transfer and this was what they used to compare other staff's practice to. There were many comments about staff practices that did not meet these ideals in regard to information transfer.

Where behaviour and performance aligned with the values held, the behaviour/performance were described as 'good or efficient' and then were described to have had positive impacts on care planning and delivery. Positive impacts were reported by staff to make their care decisions 'easy'. However, with behaviours and performance that did not align with these values (e.g. 'documentation is not always 100\%') then these practices were described as 'poor and inefficient', with negative impacts on care planning and delivery. These impacts were often described as making it 'hard' for staff to efficiently and effectively plan care and make decisions.

He came up from emergency, in the middle of the night... Everything was smooth as. It was a very good transfer. .. Everything was done that emergency stated in the handover was done. You get an accurate handover on the phone, before they bring the patient up, and face-to-face after the patient is in bed. There was no discrepancies between what was said over the phone and what I physically saw when the patient came up: Drips, 
catheter, IDC, talking, alert, orientated. We feel much better knowing what we are getting is what has been handed over to us. We don't like surprises. HDU3

\section{Information to be handed over at discharge from the ED}

Participants were also asked about what information needs to be documented and handed over. Participants were able to describe specific data items that were required to enable ongoing safe patient care (Table 2 and supplementary table). In addition they described the need for a template to prompt staff and aid the process.

The agreed essential components of information needed for information transfer for multitrauma patients were: information that was focussed on the patient; mechanism of injury; past history; clinical stability and any advance directives; their vital signs; how they responded to interventions; what interventions were conducted; as well as the treating teams involved; the future care plan; pre-hospital care given; tasks still left to complete or investigations still pending; upcoming risks; relevant orders for care; relevant family and social information and miscellaneous other information, such as property disposition and police involvement.

\section{DISCUSSION:}

\section{Best Practice}

Best practice in communication has not been well documented in the literature, with many studies calling for 'better' or 'good' communication but not defining what this means (Alvarez \& Coiera 2006). Participants in this study also had difficulty defining what 'good' communication was and found it easier to define what 'poor' communication was. For trauma patients on discharge from the ED 'good' communication was concise, clear, and included relevant information based on a recent knowledge of the patient, care and treatments provided 
and how the patient responded. Some of these aspects are supported in the literature, with a number of studies stating that clinical handover must be comprehensive, time efficient and specific (Botti et al. 2009, Braun 2012) and use a common language and communication pattern (Benham-Hutchins \& Effken 2010). Another study described good handover as thorough, with an identified leader, and had characteristics of being quiet and organised (Zakrison et al. 2015).

A major challenge with interpersonal communication is its transactional nature, as communication is neither linear nor predictable (Glass 2010), and all parts of a communication event are interrelated and effect each other (Arnold \& Boggs 2007). Participants in this study concurred that communication had to be useful to the receiver so that they could put together a picture of the patient, which served as the basis for further care decisions.

In this study 'best practice' leading to good quality of information transfer, occurred if the clinician handing over the patient was in the following situation:

- the clinician had been involved in the trauma resuscitation, where the team communicated well within the resuscitation,

- information was comprehensively documented,

- the clinician was experienced in giving structured handovers,

- the patient was stable,

- the receiving clinical area was expecting the patient and had been given accurate pre-arrival information,

- the clinicians involved in the handover were listening to each other to collectively identify past treatment and future needs. 
However, if any of these factors varied, this was likely to negatively affect the information transfer for that patient, and subsequently the transition of the patient. The stability of the patient on transfer was found to be another factor that impacted on handover, with instability in patient acuity equalling chaos in the handover process, a factor found in another study of information loss for critically injured patients (Zakrison et al. 2015).

One aspect of best practice was identified as relational continuity when the clinician having cared for the patient then transferred and provided handover to the receiving staff. Relational continuity is "an ongoing therapeutic relationship between a patient and one or more providers” (Haggerty et al. 2003). Participants in this study felt that relational continuity at handover facilitated informational continuity, "the use of information on past events and personal circumstances to make current care appropriate for each individual” (Haggerty et al. 2003). Participants valued this type of continuity as it allowed them to build a more complete, relevant picture of the patient and their care needs in less time, and with less effort and considered this to be one foundation of best practice.

Nurses who had comprehensive knowledge of the patient needed to be able to present the information in an accurate and systematic way. Therefore, the next aspect of best practice identified was that information transfer should be structured and handover the minimum information needed. Another study focusing on information loss at handover from ED to ICU for critically injured trauma patients found that handover was not structured and that staff felt it needed to be, to reduce lost information and decrease variability (Zakrison et al. 2015). In the current study staff also felt that handover needed to be structured as lost or minimal information impacted on patient outcomes. One study that introduced a standardised structure to trauma handovers increased their information transfer from $73 \%$ to $93 \%$ (Ferran et al. 2008). The study performed a closed loop audit of doctors handing over orthopaedic trauma 
patients twice a day and introduced a standardised proforma to support the verbal handovers, and showed significant improvement in data transference for all areas except blood results (Ferran et al. 2008). Improved structure and clarity about what information needed to be handed over were instrumental in improvement in the information transfer reported and supports the introduction of structure and agreement about what information should be handed over and documented as a best practice principle to information transfer.

\section{How information is transferred}

During the physical handover, communication needed to focus on specific information, as well as active listening processes that ensured information was received. Receiving staff identified they needed to be able to build a picture of the patient to enable them to plan safe and appropriate care and if this was not able to be achieved then patient transition to the new care area was jeopardised. This finding is consistent with Welsh et al.’s (2010) study where over half of the nurses felt that effective handover helped them plan their ongoing work. This is very similar to the process of handover identified in a study that tried to bridge the gaps in resident handoffs in a medical ICU to improve continuity of care (Abraham et al. 2012). Abraham et al., (2012) identified three stages to resident handoff as being the pre-turnover phase, hand off and the post-turnover phase, all with systematic activities for each phase and with the success of information transferred linked to the resident being able to achieve the coordination/organisation activities of the pre-turnover phase.

ED nurses in the current study reported feeling constrained, intimidated, or ignored by receiving staff at handover and felt this impacted on the quality of their handovers and communication with receiving staff. For communication to be effective all parties need to respond and interact together, using balanced verbal, nonverbal and written communication to allow the meaning of the communication to be understood in the manner it was intended 
(Glass 2010). However, receiving staff in this current study discussed credibility and usefulness of the ED nurses' handovers and often felt their time was wasted, particularly when staff handed over with poor structure, there were gaps in information, and suspected inaccuracy of the information. That ED staff felt judged by receiving ICU staff was a feature in another study on information loss at handover (Zakrison et al. 2015), with staff in the current study linking this to their ability to transfer information effectively. Another study that considered preferred information sources for clinical decision making noted that "nurses valued information they considered to be useful, accessible, accurate and of high quality” (Marshall et al. 2011).

Some receiving staff disagreed with the ED staff perspective that it was difficult to listen and fully engage with handover while trying to settle the patient, hook them up to monitors and complete other activities. One ED nurse stated "they have only taken in 30 percent of what you have told them" (ED8). The process of multi-tasking and interruptions during communication (including handover) was of particular note in one study (Coiera et al. 2002) that found this placed a high load on staff in affecting memory and led to errors.

Participants in all areas agreed there was a need for common processes of how information was transferred as well as communication skills, knowledge, and communication tools used in clinical practice for communicating about trauma care and this was echoed in the literature (Calleja et al. 2011). With a lack of clarity around expectations for handover and patient transition at this study site, it was unsurprising that variability in expectations and the subsequent practice was identified.

Participants described the need for an interactive process for transfer of information at handover. Participants discussed the need for the receiver to actively listen and interact, 'asking the right questions', and that the more complex the patient, the more chances there 
were for issues to occur that would negatively affect the interaction. This is supported in the literature with interpersonal communication being identified as a complex and multi-layered process between at least two people (Borowitz et al. 2008). The aspect of 'asking the right questions' is a form of feedback between the receiver and sender of the message and is essential if the sender is to know if their message is being followed and understood (Arnold \& Boggs 2007). 'Asking the right questions' at handover to reduce missed information and ambiguity was also identified in a study of nursing handovers in medical wards in Australia (Liu et al. 2012). In this study when inexperienced nurses took handover from the ED staff they were not able to identify the right questions to ask to clarify the information needed to continue to provide safe care (Liu et al. 2012). Ambiguities were made up of incomplete communication such as initial diagnosis, specific patient care requirements, ongoing treatment and newly prescribed medication. Ambiguity and missed information in handover was also linked to increased risk for adverse patient events (Liu et al. 2012).

Information was transferred in multiple ways in this study. While participants in the current study preferred having a verbal handover, they valued documented information more. This contrasts with findings in Benham-Hutchins and Effken’s (2010) study in which verbal communication was preferred by clinicians when exchanging patient information.

Additionally, Cheung et al., (2010) identified that where the receiving clinician could not build an adequate picture of the patient from handover, the post-handover period was used to further evaluate the patient and documentation in an attempt to complete the picture of the patient. This may support why clinicians in the current study valued written information more than verbal information, as in their experience it was more useful during the post-handover period as an available resource to assist in building a picture of the patient. 
How information was transferred was also affected by specialty bias. The researcher noted distinct references to culture and stereotyping of nurses, by nurses from other care areas, according to where they worked and has referred to this as a specialty bias. From focus group interactions the researcher noted that nurses did not seem to understand nurses from other specialities (e.g. ICU vs ED) in terms of their expectations, perspectives and realities of care environments, unless they had worked in those areas. In this study it seemed that the culture in a unit about information transfer was driven by specialty biases, as well as individual and collective attitudes and practices. This was another common feature in Zakrison et al.'s (2015) study, where findings indicated a lack of understanding between clinical areas of each other's’ working conditions or challenges their clinical areas contained.

Often fragmentation in care for trauma patients impacted on how information was transferred between areas. Fragmentation applied to practice related to broken links in documented or duplicated information, missing information due to patient acuity overtaking ability to document the treatment in time; time imperatives which affected each clinical area differently; and discrepancies between documented information or verbal and documented information. If staff were unable to clarify information and therefore experienced a broken link to information validity, this resulted in an information flow breakdown (Abraham et al. 2012). Another study described looking for and finding lost information as information rescue, and that in cases where information was rescued as many as one in three patients had their clinical management changed in the ICU (Zakrison et al. 2015). Fragmentation and duplication for emergency patients has also been found in other studies as an issue impacting on the complexity of care (Kilner \& Sheppard 2010).

At times patients who were transferred from the ED had conflicting orders about their care. In trying to build a picture of the patient, participants found this confusing and frustrating, and 
reported that this impacted on immediate and longer term patient outcomes. For example, one participant described conflicting orders from two different medical teams involved in one patient's care around being nil by mouth or on a light diet. Nurses did not find the nil by mouth order until after the patient had been fed and this delayed surgery until the next day. This example showed a lack of care coordination by care leaders, as different medical teams were involved in the care. The blurring of who is leading patient care where multiple teams are involved has been identified as a cause of frustration in other studies (Sarcevic et al. 2011) and has been reported to impact on patient outcomes.

Variability in how information was communicated also impacted on how information was transferred. Variability in this regard was not an expected finding, as communication is a core competency, and expectations of high quality communication are the norm for health care professionals. This is reflected in the law and regulations by which health care professionals are bound. An important professional expectation for clinicians is to provide therapeutic communication that is not superficial and generates meaning and understanding (Glass 2010, Johnstone 2009, O'Toole 2008, Stein-Parbury 2009). However, trauma care is considered a specialised type of health care as a result of having many more clinicians involved in the patient's care which often needs to be provided more rapidly than in other areas of the health care environment, with decisions often made with incomplete information. It must be noted that processes that may work in less stressful, less acute situations do not always translate to trauma care situations (Mackenzie et al. 2004) due to the increased patient and team complexity, patient acuity and focus of care, which are time pressured.

\section{Information to be handed over or documented}

Information to be handed over or documented comprised of the elements that make up a thorough assessment of the patient's situation, status, treatments, ongoing care requirements 
and upcoming interventions. None of the data is additional to what a thorough head to toe or systems based assessment including health and social history. The data that was identified as being essential for multi-trauma patients emphasises elements required for these complex patients. This list provides specific data identified by staff required for handover and documentation that has not been found to be published elsewhere and may form the basis for intervention when considering strategies to improve information transfer. While structure and consistency is called for by participants in this study and others (Zakrison et al. 2015) we felt we needed to know what information staff valued to be communicated at transition points.

\section{Strengths and limitations}

Strengths and limitations in this study were specifically related to method choice and the strategies we applied to mitigate limitations. In using focus groups to identify specific issues and associated details, one limitation was whether the issue to be discussed was too sensitive (Happell 2007). In this study however, communication of patient information was, in the researcher's opinion, not apparently sensitive for group members to discuss openly, as long as they were within their own clinical areas. When staff were discussing these issues later in a mixed group this dynamic changed and group members seemed to find this topic and discussion about barriers and conduits to effective information transfer more sensitive, and discussions were more often easily inflamed and argumentative. A further limitation was that this study was conducted in a single site, metropolitan ED. Single site studies may limit generalisability of findings to other clinical site which may use different approaches, and have different policies and procedures.

A strength of this study was that all participants were able to reach consensus in the groups and were able to validate meaning within the group due to group size, validation techniques 
of the researcher and in review transcripts post focus group. This method also allowed clinicians to give voice to their experiences authentically.

\section{CONCLUSION:}

Information transfer for multi-trauma patients is integral to the continuing care patients receive across their acute care journey. Four themes of variability, continuity, putting together the pieces and values/context all impacted on the quality of information transferred for this patient group. Specific information proposed by staff to be handed over included details of patient identification, current and proposed treatment, response to interventions, acuity and stability/status along with information about property, family, psychosocial issues and if police or social work had been involved. Best practice identification for information transfer was seen by staff to be clear and concise information, pertinent communication at handover, relevant clear documentation that travelled with the patient, handover communication engaged in by both sender and receiver, and processes which were standardised and met the needs of all involved.

\section{RELEVANCE TO CLINICAL PRACTICE}

The relevance of the findings to clinical practice relate to three discrete areas: individual clinical practice; education of clinicians; and, further research. Improvement in handover requires each staff member to take personal responsibility to actively engage in listening, avoid 'doing' tasks at the same time as listening, and to be prepared for handover before transfer of the patient. Receiving staff should be aware of any questions they may need to ask during handover to ensure the information transferred will best support patient care planning and transition into the new care area. Expectations of what information needs to be transferred at transition to different care areas need to orchestrated and communicated. An organisation-wide approved communication structure is imperative (to convey the required 
data needed to continue care for the patient) such as SBAR or others, both for documentation and handover. Expectations surrounding documentation of patient care are that documentation should be comprehensive and ensure clarity of care plans and trends for how patients have responded to interventions. Organisational processes where possible should support the provision of relational continuity for patient transfer and handover, for example the clinician who has been involved in the care is the same person to transfer the patient to a different clinical area.

Organisational based education on handover approaches that are based on best practice principles, emphasising the dual responsibility of clinical handover for both the giver and receiver is crucial. Few training programs formally teach clinicians how to handover and even fewer assess handover skills (Borowitz et al. 2008). Goals and characteristics of a concise and complete handover must be defined before curricula can be implemented (Borowitz et al. 2008). In the current study, goals and characteristics of what information must be transferred for trauma patients leaving the ED have been identified, and this could be used as the basis for curriculum development. Within each specialty environment staff need to be educated on how to ask the 'right' questions during handover. This may be very specific to their models of care, the type of care environment and clinician scope of practice.

Further research include identifying and testing interventions or strategies that may improve information transfer in the clinical context where patient transfer spans different clinical units and disciplines for multi-trauma patients is needed. 
Table 2: Information required to handover or document at transfer for multi-trauma patients

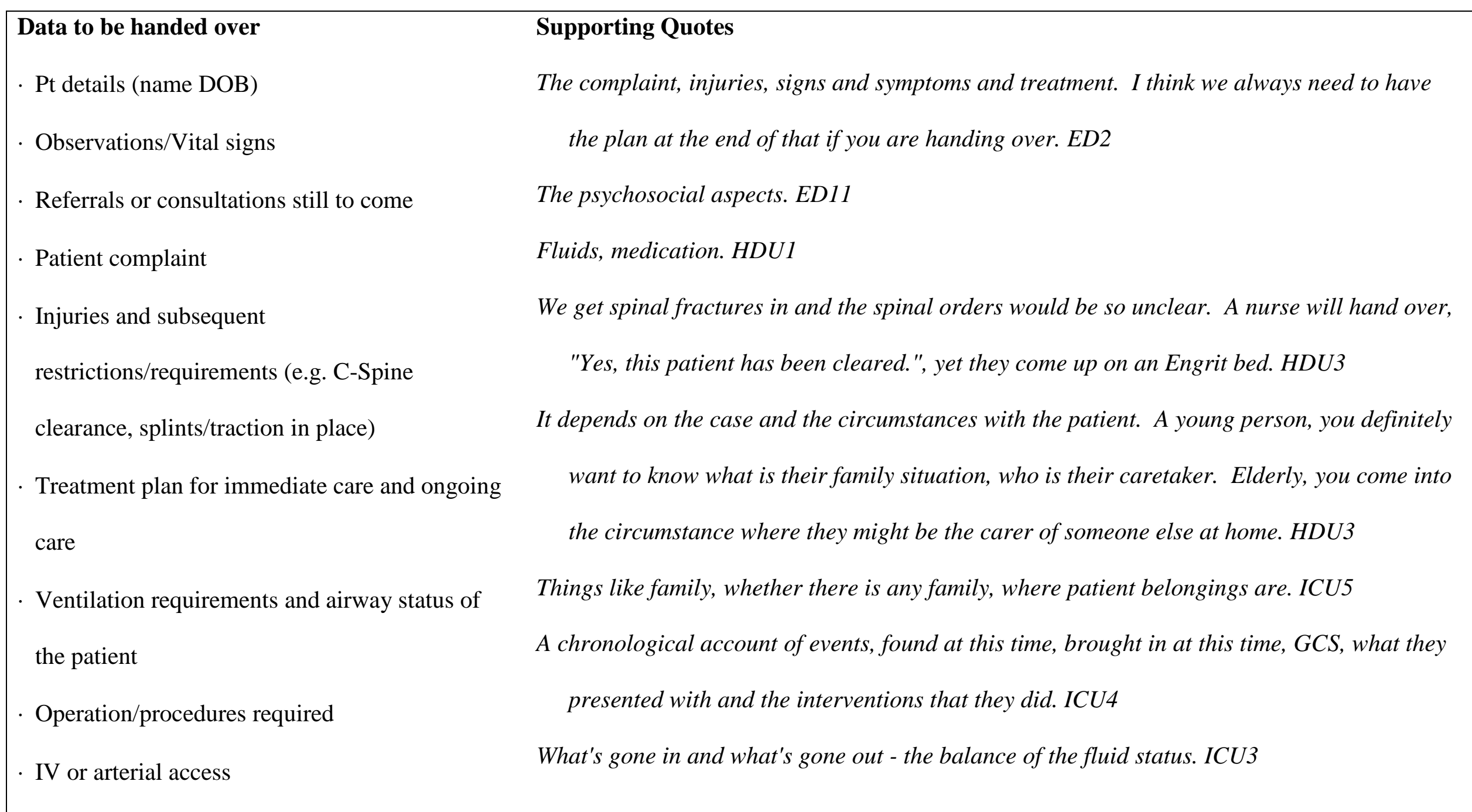




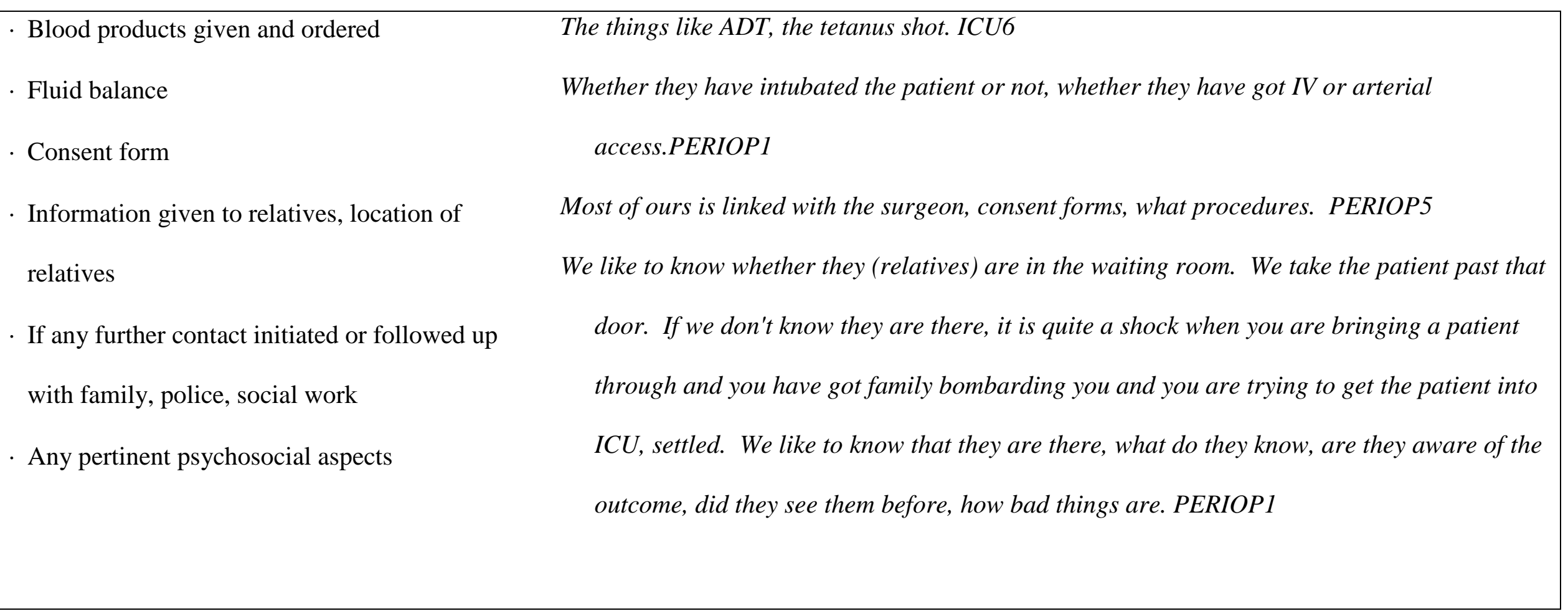


Supplementary table

\begin{tabular}{|c|c|c|}
\hline Theme & Subtheme and explanation & Quotes \\
\hline Variability & $\begin{array}{l}\text { Expectations: } \\
\text { Expectations of handover and documentation varied between units and } \\
\text { there was no standard in place for handover. } \\
\text { Different areas believed they should be able to have information specific } \\
\text { to their needs, whereas ED staff approached handover from the } \\
\text { perspective of reporting what was done in ED. } \\
\text { Staff agreed that clear expectations were needed to reduce fragmentation } \\
\text { of information at handover, as serious outcomes can be attributed to } \\
\text { poor information transfer. }\end{array}$ & $\begin{array}{l}\text { Every institution I have worked at, there is the general } \\
\text { animosity between nursing staff, especially in critical } \\
\text { care areas... We are specialised in our little nook and } \\
\text { our way is the right thing to do from our point of view. } \\
\text { We want to hear handover, head to toe, chronological, } \\
\text { covering everything, including the last time they wiped } \\
\text { their bottom. ED and theatre don't care. I don't think } \\
\text { we are going to find a perfect match. If we had a tick } \\
\text { and flick, that would be so much easier. ICU3 }\end{array}$ \\
\hline & $\begin{array}{l}\text { Skills and knowledge: } \\
\text { Variability in skills or knowledge was evident in staff perceptions about } \\
\text { what was important to handover about patient care, how well different } \\
\text { staff gave handover. }\end{array}$ & $\begin{array}{l}\text { I think it depends on the person who is handing } \\
\text { over...There are some great handovers you would like } \\
\text { to keep with the senior nurses looking after the } \\
\text { patients all the time but that doesn't always happen. }\end{array}$ \\
\hline
\end{tabular}




\begin{tabular}{|c|c|}
\hline & TSU1 \\
\hline $\begin{array}{l}\text { Information staff chose to handover or document: } \\
\text { The comprehensiveness and quality of the information that was handed } \\
\text { over and documented was variable. If inexperienced staff were } \\
\text { providing care then there could be more variation in what was seen as } \\
\text { important to document or handover. } \\
\text { Issues with information quality were compounded if the patient was } \\
\text { transferred by a nurse from the ED who had not been caring for the } \\
\text { patient. When this occurred trust in the handover was impacted on and } \\
\text { a frustrated and dismissive attitude was displayed by receiving staff } \\
\text { and a greater emphasis on documented information results. } \\
\text { Each group agreed that a minimum data set was necessary to define and } \\
\text { be the basis for handover and documentation. The agreed goal of } \\
\text { documentation of patient care was that it be relevant, of high quality } \\
\text { but essentially simple and straightforward. }\end{array}$ & $\begin{array}{l}\text { We have a problem with paper notes not always coming } \\
\text { up with the patient so we don't always have a plan. } \\
\text { The nurse may not know that because the doctor has } \\
\text { not told her. You will get the patient and you will say, } \\
\text { "Are they nil by mouth?" The nurse may not know. } \\
\text { You can't check the plan. TSU1 } \\
\text { That is a problem for not only the nurse leaving ED } \\
\text { because she does not know the patient. It is also a } \\
\text { problem for the nurse receiving the patient. It is hard } \\
\text { to know how much to believe from a nurse who has } \\
\text { not looked after them. You can't question them about } \\
\text { anything. TSU1 } \\
\text { Basically, every day is the same. You need same basic } \\
\text { information. When you look at this documentation you } \\
\text { must have a firm understanding to take adequate }\end{array}$ \\
\hline
\end{tabular}




\begin{tabular}{|c|c|c|}
\hline & & $\begin{array}{l}\text { action and adequate knowledge about this patient. } \\
\text { TSU-S1 }\end{array}$ \\
\hline & $\begin{array}{l}\text { Quality of information transfer: } \\
\text { Good information transfer consisted of three main elements. } \\
\text { 1. comprehensive information about the patient and care given was } \\
\text { handed over and written down. } \\
\text { 2. the person who provided nursing care for the patient during the } \\
\text { resuscitation period was the one who handed the patient over } \\
\text { 3. information was accurate and systematic. }\end{array}$ & $\begin{array}{l}\text { It means you have got a good handover regarding the } \\
\text { physical condition of the patient, the socioeconomic } \\
\text { and emotional sections of what is happening with the } \\
\text { patient. The management plan on top of all of } \\
\text { that - that would be comprehensive. TSU3 }\end{array}$ \\
\hline & $\begin{array}{l}\text { Processes Used: } \\
\text { Processes should be simple and easy to improve to maintain compliance } \\
\text { rates with templates. Handover had poor or no structure and was } \\
\text { unsystematic. Handover should focus on reporting trends in patient } \\
\text { condition and response to treatment. }\end{array}$ & $\begin{array}{l}\text { It doesn't matter how much paperwork it is, it is never } \\
\text { completed. Whatever you do is going to have to be } \\
\text { simple and easy because nobody complies. ED9 }\end{array}$ \\
\hline Continuity & $\begin{array}{l}\text { Continuity of multiple clinicians: } \\
\text { People and relational discontinuity was usually exacerbated if the nurse }\end{array}$ & $\begin{array}{l}\text { We see between one to eight consultants from various } \\
\text { groups involved in the care of the single patient, and }\end{array}$ \\
\hline
\end{tabular}




\begin{tabular}{|c|c|}
\hline $\begin{array}{l}\text { who provided care for the patient in the trauma area was not the person } \\
\text { who transferred and handed over that patient. } \\
\text { The higher the number of people involved in the care of these patients } \\
\text { increased the complexity in knowing who was responsible for what. }\end{array}$ & $\begin{array}{l}\text { you list all those different players as much as you } \\
\text { know right from the beginning, which makes it much } \\
\text { easier to follow up the patient within the system. This } \\
\text { is just one example which is extremely important for } \\
\text { the on-going management of a patient. TSU-S1 }\end{array}$ \\
\hline $\begin{array}{l}\text { Broken Links: } \\
\text { Impact of broken links took the form of duplication of patient information, } \\
\text { inaccurate or missed information being perpetuated for a number of } \\
\text { days, or patient information in multiple places within the chart making } \\
\text { looking for information difficult and time consuming. } \\
\text { Broken links also referred to documentation not showing an accurate } \\
\text { picture of the patient care given, often due to the acuity of the patient. }\end{array}$ & $\begin{array}{l}\text { I see duplication in information from the front door all } \\
\text { the way through. We should rather streamline this to } \\
\text { have more quality in the documentation. TSU-S1 } \\
\text { It can have an impact on a patient... At the end of the } \\
\text { day, we may feed a patient who is supposedly going to } \\
\text { theatre and we may cancel it. If we don't feed a patient } \\
\text { when we could have, you have got inadequate } \\
\text { nutrition so it has implications for the patient. TSU1 }\end{array}$ \\
\hline $\begin{array}{l}\text { Time imperatives: } \\
\text { Having enough time and patient acuity and time of day were all seen to be } \\
\text { factors affecting broken links for information transfer. }\end{array}$ & $\begin{array}{l}\text { You are scooping for time; you are writing as you are } \\
\text { going up the lift. ED3 } \\
\text { I think people are too quick to get back to their own area. }\end{array}$ \\
\hline
\end{tabular}




\begin{tabular}{|c|c|}
\hline $\begin{array}{l}\text { People rushing back to their work areas and not taking enough time to } \\
\text { comprehensively handover the patient } \\
\text { Patient acuity impacted on how much time was spent at the handover, } \\
\text { sometimes if the patient was deteriorating, or their condition had } \\
\text { changed during transfer, then the handover would be cut short to attend } \\
\text { to the patient's needs. } \\
\text { Time of day was an issue in some areas. For the perioperative area, night } \\
\text { time was seen as easier to manage handover, however, in ICU this was } \\
\text { the most difficult time of day for them to receive handover. }\end{array}$ & $\begin{array}{l}\text { People rush in, give you the patient. "Okay, well, I } \\
\text { have got another patient to get back to" - so quick, } \\
\text { quick, quick... People are too rushed, to give adequate } \\
\text { handover and make sure we know everything that is } \\
\text { going on. HDU2 } \\
\text {... at night-time it is easier because the team is } \\
\text { smaller...You know what each person is trying to get } \\
\text { out of that handover. During the day-times, you have } \\
\text { got a lot of people talking and nobody is getting all the } \\
\text { information. PERIOP1 }\end{array}$ \\
\hline $\begin{array}{l}\text { Processes of information transfer: } \\
\text { Various processes exacerbated 'broken links'. This included information } \\
\text { often being received by the clinical area before the patient arrived (e.g. } \\
\text { bed manager, ED shift coordinator etc.), with varying levels of } \\
\text { accuracy and specificity. } \\
\text { The process of information transfer started at the time they were advised }\end{array}$ & $\begin{array}{c}\text { The doctors do a handover to the other doctor and the } \\
\text { nurses do a handover to the other nurse...it is a bit } \\
\text { silly. Medical handover can occur at any place. The } \\
\text { nursing handover occurs at delivery. ED7 } \\
\text { There is talking and listening. It has got to be separate. } \\
\text { The person giving the handover talks and the other }\end{array}$ \\
\hline
\end{tabular}




\begin{tabular}{|c|c|}
\hline $\begin{array}{l}\text { they were receiving a patient from the ED (which may have been be } \\
\text { hours before they actually arrived). } \\
\text { Handovers were usually single discipline and conducted by nursing staff, } \\
\text { as medical handover was often given over the telephone and at varying } \\
\text { points in the patient journey from the ED to the clinical area. }\end{array}$ & $\begin{array}{l}\text { one has to listen. When it has gone badly is because } \\
\text { they are not listening. There has got to be a defined } \\
\text { role. ED7 }\end{array}$ \\
\hline $\begin{array}{l}\text { Discrepancy of information: } \\
\text { Discrepancy of information refers to the differences between the } \\
\text { information handed over and what was documented, and being able to } \\
\text { access to that documentation. } \\
\text { In instances where the patient notes were not with the patient, nurses said } \\
\text { they must then trust the verbal information to provide care for the } \\
\text { patient in the interim, but this was difficult when there were } \\
\text { discrepancies. However having the patient notes arrive with the patient } \\
\text { did not solve issues of what to do when there were discrepancies in the } \\
\text { information. When it did staff then had to go through a complicated } \\
\text { problem solving process due to contradictions in the documented }\end{array}$ & $\begin{array}{l}\text { Sometimes we get two subspecialties, a surgeon and } \\
\text { orthopaedic. They are slightly different. One will say, } \\
\text { "Nil by mouth.", and the other will say, "Light diet." } \\
\text { TSU1 } \\
\text { If they say we have given this and later we check to see if } \\
\text { they have written it up somewhere, if they have not } \\
\text { written it on the fluid chart, then we are going to } \\
\text { assume that they have not had it. With the blood } \\
\text { products, we can chase it. You assume if it has been } \\
\text { taken out of the blood bank and they say it has been } \\
\text { given - you make a lot of assumptions that it has been }\end{array}$ \\
\hline
\end{tabular}




\begin{tabular}{|c|c|c|}
\hline & $\begin{array}{l}\text { information or the patient condition, they had to try to determine which } \\
\text { parts of the documentation could be trusted. }\end{array}$ & given. PERIOP1 \\
\hline $\begin{array}{l}\text { Putting the } \\
\text { pieces } \\
\text { together }\end{array}$ & $\begin{array}{l}\text { Putting together a picture: } \\
\text { In order to build a picture of the patient the staff handing over the patient } \\
\text { needed to know the patient to be able to pass on the required } \\
\text { information. } \\
\text { Receiving staff identified often having to search for information once they } \\
\text { established it was missing and often could not find out what they } \\
\text { needed to know. }\end{array}$ & $\begin{array}{l}\text { If you are dealing with patients, you need to know what is } \\
\text { going on with them, what infusions they have, what } \\
\text { their medical history is, how they are neurologically, } \\
\text { just to be safe. HDU2 }\end{array}$ \\
\hline & $\begin{array}{l}\text { Patient transition: } \\
\text { Patient transition related to how easily the patient was admitted and settled } \\
\text { into the clinical area as a result of information transfer. Poor handover, } \\
\text { missing information, or inaccurate information impacted on the ability } \\
\text { of staff to effectively put together a picture of what care is required to } \\
\text { address patient needs. Accurate information conveyed to the clinical } \\
\text { staff before the patient arrived eased transition and admission and }\end{array}$ & $\begin{array}{l}\text { If we get a good referral to the medical staff and they } \\
\text { communicate that well to us, we can help facilitate } \\
\text { that easier. They can give us the majority of } \\
\text { information because they have had that in-depth } \\
\text { handover. That can help us prepare and maybe the } \\
\text { handover from the ED staff doesn't need to be as in } \\
\text { depth because we have all the information available to }\end{array}$ \\
\hline
\end{tabular}




\begin{tabular}{|c|c|}
\hline allowed staff to focus on patient issues at handover. & us. ICU6 \\
\hline $\begin{array}{l}\text { Planning safe patient care: } \\
\text { When handovers were not comprehensive and documentation was poor, } \\
\text { participants reported that decision making for immediate care planning } \\
\text { was difficult. When handovers were of adequate comprehensiveness } \\
\text { this helped alleviate stress on staff that were already busy planning and } \\
\text { carrying out care. } \\
\text { With documented information, staff felt it was useful at the start of their } \\
\text { care for the patient and handing on relevant information to oncoming } \\
\text { care givers and measuring patient progress or condition changes. }\end{array}$ & $\begin{array}{l}\text { It can be so busy and, even though you have got handover } \\
\text { from the nurse previously, you don't have time to go } \\
\text { through the forms. There should be enough } \\
\text { information for you to care for that patient properly. } \\
\text { Until you have time to read go through the forms, it } \\
\text { shouldn't be relied on that you can read the notes. } \\
\text { HDU2 }\end{array}$ \\
\hline $\begin{array}{l}\text { Missing pieces: } \\
\text { Missing pieces related to the difficulty in finding information that may or } \\
\text { may not have been documented or handed over, the need to see when a } \\
\text { patient's condition changed, diagnoses made (or missed) for purposes } \\
\text { of tertiary survey and patient quality review processes. }\end{array}$ & $\begin{array}{l}\text { There is not much to look at in the paperwork. It is } \\
\text { usually not filed in any (order) - the chart is a big pile } \\
\text { of medical notes that - the paperwork is so } \\
\text { disorganised and so there is no point. You are just } \\
\text { wasting time. Often it is not until it gets filed by our } \\
\text { ward staff that you can make sense of it or find things. }\end{array}$ \\
\hline
\end{tabular}




\begin{tabular}{|c|c|c|}
\hline & & $\begin{array}{l}\text { The medical notes are often written on separate pages. } \\
\text { The multi-trauma team will all grab a new piece of } \\
\text { paper and chuck it on the chart. There is a loss of } \\
\text { communication there. ICU6 }\end{array}$ \\
\hline $\begin{array}{l}\text { Values/ } \\
\text { context }\end{array}$ & $\begin{array}{l}\text { Documentation was seen as medico-legally important and was a source of } \\
\text { the 'real' story, as it was acknowledged that verbal communication can } \\
\text { become 'Chinese whispers' and therefore inaccurate. Basic } \\
\text { assumptions were also made in regard to care given as a result of } \\
\text { documentation. Documentation was seen as a safety mechanism in } \\
\text { legal processes. } \\
\text { Where there were discrepancies between the information handed over and } \\
\text { documented participants described documentation as being more } \\
\text { valuable than verbal information. } \\
\text { Specific information relevant to ongoing care was valued over broad or } \\
\text { general information. }\end{array}$ & $\begin{array}{l}\text { The handovers are in a certain way important but the } \\
\text { turnover of staff, the amount of staff that would look at } \\
\text { the document, the written document, is extremely } \\
\text { important. TSU-S1 } \\
\text { Legally, you can't stand up in a court of law and say } \\
\text { "Well, she said...". It is all hearsay. If it is not } \\
\text { documented, it hasn't happened. The valued } \\
\text { communication - it is more valuable, written. We all } \\
\text { make mistakes. "Did she say } 100 \text { or } 10 \text { ?" It is written } \\
\text { here... ED3 }\end{array}$ \\
\hline
\end{tabular}




\section{Reference List}

Abraham J, Kannampallil TG \& Patel VL (2012): Bridging gaps in handoffs: A continuity of care based approach. Journal of Biomedical Informatics 45, 240-254.

Alvarez G \& Coiera E (2006): Interdisciplinary communication: an uncharted source of medical error? Journal of Critical Care 21, 236-242.

Arnold E \& Boggs KU (2007) Interpersonal Relationships. Saunders Elsevier, St. Louis.

Benham-Hutchins MM \& Effken JA (2010): Multi-professional patterns and methods of communication during patient handoffs. International Journal of Medical Informatics 79, 252-267.

Bergs EA, Rutten FL, Tadros T, Krijnen P \& Schipper IB (2005): Communication during trauma resuscitation: do we know what is happening? Injury, International Journal of The care of the Injured 36, 905-911.

Borowitz SM, Waggoner-Fountain LA, Bass EJ \& Sledd RM (2008): Adequacy of information transferred at resident sign-out (in-hospital handover of care): a prospective survey. Quality and Safety in Health Care 17, 6-10.

Botti M, Bucknall T, Cameron P, Johnstone MJ, Redley B, Evans S \& Jeffcott SA (2009): Examining communication and team performance during clinical handover in a complex environment: the private sector post-anaesthetic care unit. MJA 190, s157-s160.

Braun BD (2012): Evaluating and improving the handoff process. Journal of Emergency Nursing 38, 151-155.

Calleja P, Aitken LM \& Cooke ML (2011): Information transfer for multi-trauma patients on discharge from the emergency department: mixed method narrative review. Journal of Advanced Nursing 67, 4-18.

Cheung DS, Kelly JJ, Beach C, Berkeley RP, Bitterman RA, Broida RI, Dalsey WC, Farley HL, Fuller DC, Garvey DJ, Klauer KM, McCullough LB, Patterson ES, C. PJ, Phelan MP, Pines JM, Schenkel SM, Tomolo A, Turbiak TW, Vozenilek JA, Wears RL \& White ML (2010): Improving handoffs in the emergency department. Annals of Emergency Medicine 55, 171-180.

Coiera EW, Jayasuriya RA, Hardy J, Bannan A \& Thorpe MEC (2002): Communication loads on clinical staff in the emergency department. Medical Journal of Australia 176, 415-418.

Cole E \& Crichton N (2006): The culture of a trauma team in relation to human factors. Journal of Clinical Nursing 15, 1257-1266.

Denscombe M (2007) The good research guide for small scale social research projects., 3rd edn. McGraw-Hill/Open University Press, Maidenhead, Berkshire, United Kingdom.

Ferran NA, Metcalfe AJ \& O'Doherty D (2008): Standardised proformas improve patient handover: Audit of trauma handover practice. Patient Safety in Surgery 2, 1-5.

Glass N (2010) Interpersonal relating. Health care perspectives on communication, stress and crisis. Palgrave Macmillan, South Yarra.

Haggerty JL, Reid RJ, Freeman GK, Starfield BH, Adair CA \& McKendry R (2003): Continuity of care: a multidisciplinary review. BMJ 327, 1219.

Happell B (2007): Focus groups in nursing research: an appropriate method or the latest fad? Nurse Researcher 14, 18-24.

Johnstone MJ (2009) Bioethics: a nursing perspective, 5th edn. Elsevier, Chatswood.

Kilner E \& Sheppard LA (2010): The role of teamwork and communication in the emergency department : a systematic review. International Emergency Nursing 18, 127-137.

Liu W, Manais E \& Gerdtz M (2012): Medication communication between nurses and patients during nursing handovers on medical wards: a critical ethnographic study. International Journal of Nursing Studies 49, 941-952.

Mackenzie CF, Xiao Y \& Horst R (2004): Video task analysis in high performance teams. Cognition, Technology \& Work 6, 139-147. 
Marshall AP, West SH \& Aitken LM (2011): Preferred information sources for clinical decision making: critical care nurses' perceptions of information accessibility and usefulness. Worldviews on Evidence-Based Nursing Fourth Quarter, 224-235.

McFetridge B, Gillespie M, Goode D \& Melby V (2007): An exploration of the handover process of critically ill patients between nursing staff from the emergency department and the intensive care unit. Nursing in Critical Care 12, 261-269.

Norwood SL (2010) Research essentials: foundations for evidence-based practice. Pearson, Boston. O'Toole G (2008) Communication: core interpersonal skills for health professionals. Elsevier, Sydney. Sarcevic A, Marsic I, Waterhouse LJ, Stockwell DC \& Burd RS (2011): Leadership structures in emergency care settings: a study of two trauma centers. International Journal of Medical Informatics 80, 227-238.

Stein-Parbury J (2009) Patient and person: developing interpersonal skills in nursing, 4th edn. Elsevier, Sydney.

Sugrue $M$, Seger M, Kerridge R, Sloane D \& Deane S (1995): A prospective study of the performance of the trauma team leader. The Journal of Trauma, Injury, Infection, and Critical Care 38, 7982.

Webb C \& Kevern J (2001): Focus groups as a research method: a critique of some aspects of their use in nursing research. Journal of Advanced Nursing 33, 798-805.

Welsh CA, Flanagan ME \& Ebright P (2010): Barriers and facilitators to nursing handoffs: recommendations for redesign. Nursing Outlook 58, 148-154.

World Health Organization (2007) Communication during patient hand-overs (WHO ed.). World Health Organization - collaborating centre for patient safety solutions.

Xiao Y \& Moss J (2001): Practices of high reliability teams: observations in trauma resuscitation. Human factors and ergonomics society annual meeting proceedings 45, 395-399.

Xiao Y, Schenkel S, Faraj S, Mackenzie CF \& Moss J (2007): What whitebaords in a trauma center operating suite can teach us about emergency department communication. Annals of Emergency Medicine 50, 387-395.

Zakrison TL, Rosenbloom B, McFarlan A, Jovicic A, Soklaridis S, Allen C, Schulman C, Namias N \& Rizoli $S$ (2015): Lost information during the handover of critically injured trauma patients: a mixed-methods study. BMJ Quality \& Safety 0, 1-8. 